\title{
TRADUÇÃO
}

\section{A "EPÍSTOLA SOBRE O INTELECTO", DE AL-KINDI}

Tadeu M. Verza* verza@ufmg.br

Al-Kindi (?800 - ?870) foi o primeiro a produzir textos em árabe seguindo a tradição do pensamento filosófico grego, sendo, portanto, visto como o primeiro filósofo da falsafa. ${ }^{1}$ Ele também foi uma figura importante na promoção e transmissão das traduções de textos filosóficos gregos para o árabe por meio do que foi chamado seu "círculo". ${ }^{2}$

O texto que aqui apresento traduzido, a "Epístola sobre o intelecto" ("Risala fi al-'aql"), é um opúsculo fundamental para a compreensão da entrada das questões relativas à alma no mundo islâmico, mesmo que as fontes da "Epístola" ainda sejam fruto de discussão. Muito já foi escrito sobre este texto e julgo que basta no momento remeter a seus principais comentadores. ${ }^{3}$

Traduzi o texto a partir da edição de Abu Rida (1953, pp. 353-357), do qual sigo a numeração das páginas, e comparei com a de McCarthy (1964, pp. 119-149) e com a de Jolivet (1971, pp. 158-160). Das traduções, consultei as de McGinnis e Reismann (2007, pp. 16-18), Jolivet (1971, pp. 1-6), Ruffinengo (1997, pp. 347-356), Atiyeh (1966, pp. 211-215) e a de Ramón Guerrero e Tornero Poveda (1986, pp. 150-152). Optei por traduzir seguindo, na medida do possível, a ordem do texto árabe.

* Professor do Depto. de Filosofia da UFMG. Tradução recebida em 30/04/2014 e aprovada em 25/07/2014.

1 Para uma visão de conjunto sobre al-Kindi e sua obra, ver Atiyeh (1966); Tornero Poveda (1992); Adamson (2007).

2 Sobre sua atuação e a existência do "círculo de al-Kindi", ver, entre outros, Fazzo e Wiesner (1993); Endress (1997); Adamson (2007a, pp. 41-45); Adamson (2010); Adamson (2004); Mossa (1967); Endress (2004); Adamson (2007b).

3 D’Ancona (1999); Fitzmaurice (1971); Ruffinengo (1997); Wiesner (1993); Adamson (2007).

KRITERION, Belo Horizonte, $n^{\circ}$ 131, Jun./2015, p. 291-295 
Em nome de Deus, o clemente, o misericordioso

Em Deus [reside] o poder.

Epístola de Abu Yusuf Ya'qub ibn Ishaq al-Kindi sobre o intelecto.

$[353.5]^{4}$ Que Deus faça com que compreendas todos ${ }^{5}$ os benefícios [que ele vos concede] e que garanta a ti felicidade no mundo dos vivos e no mundo dos mortos.

[353.5-10] Compreendi que pedistes um breve relato explicativo descrevendo a doutrina do intelecto (' $a q l$ ) segundo a opinião dos louváveis antigos gregos. Os mais louváveis entre eles são Aristóteles e seu professor, o sábio Platão. Na medida em que a essência (hasil) do discurso de Platão sobre isso é [a mesma] da de seu discípulo Aristóteles, tratemos disto pela via explicativa.

[353.10-354.6] Dizemos que a opinião de Aristóteles sobre o intelecto é que o intelecto é de quatro tipos. O primeiro deles é o intelecto que está sempre em ato. $\mathrm{O}$ segundo é o intelecto em potência, e este pertence à alma (li-l-nafs). O terceiro é o intelecto que passa, na alma, da potência ao ato. $\mathrm{O}$ quarto | é o intelecto que chamamos de segundo. ${ }^{6}$ [Aristóteles] compara o intelecto aos sentidos devido à proximidade dos sentidos com o ser vivo e [porque] a prevalência [dos sentidos] nos [seres vivos] é total. Ele diz que a forma é de dois [tipos]: um é a forma na matéria e que ocorre sob os sentidos; outro é aquela que não possui, por si (dhat), matéria, ocorrendo sob o intelecto e sendo a especificidade das coisas e o que está acima delas. Então, a forma que está na matéria é perceptível ${ }^{7}$ em ato, pois se não fosse perceptível em ato não recairia sob os sentidos.

[354.6-355.3] Quando a alma adquire [a forma], ela está na alma, mas a alma a adquire porque [a forma] está na alma em potência. Quando a alma adquire [a forma], ela está na alma em ato. Porém, [a forma] não está na alma

Os números entre colchetes referem-se ao número da página e linhas da edição de Abu Rida (1953). Usase barra vertical para indicar quebra de página.

5 Jolivet (1971) e McCarthy (1964) inserem jamiya', faltante em Abu Ridah (1953).

6 McCarthy (1964) alerta para o fato de este termo no manuscrito não possuir pontuação diacrítica (nuqtah), o que pode levar a uma série de leituras. Na edição de Abu Ridah lê-se "al-thaniyah" (o segundo) e na de McCarthy lê-se "al-natiyah" (o emergente). Badawi, em sua introdução à edição da versão árabe do "De anima", sugere que se leia al-ba'in ou al-bayani (ser evidente, claro) (Badawi, 1980, pp. 6-7). McCarthy argumenta que ler "al-natiyah" é coerente com a descrição que al-Kindi fornecerá deste intelecto em 358:4 como o "intelecto que se manifesta (al-tahir)". Porém Jolivet mantém a leitura por "segundo", e seu argumento (p. 13) tem aspectos históricos e doutrinais: a expressão "intelecto segundo" é utilizada na "Teologia de Aristóteles" e no "Liber de causis" e al-Kindi a usa ao se referir ao intelecto como "causa [...] de todos os inteligíveis e dos intelectos segundos" (357, p. 4). Sigo a leitura de Abu Ridah (1953) e Jolivet (1971).

7 Isto é, percebida por meio dos sentidos. 
como uma coisa em um recipiente nem como uma marca em um corpo, pois a alma | não é corpo nem divisível. Logo, [a forma] no corpo e a alma são uma coisa [só], não [coisas] diversas, nem há [entre elas] uma diversidade (ghairiyyah) pela diversidade dos predicados.

[355.3-8] Também, do mesmo modo, a faculdade sensitiva não é uma coisa diversa da alma nem está na alma como um órgão está no corpo; antes, ela é a alma e ela é o que sente. Do mesmo modo, a forma percebida [pelos sentidos] não é na alma outra [coisa que não a própria alma] nem é uma diversidade [na alma]. Assim, o que é percebido, na alma, é o que sente. ${ }^{8}$ Quanto à matéria (hayula), o que é percebido dela é distinto da alma que sente. Assim, no que tange à matéria, o que é percebido não é o que sente.

[355.9-356.5] Desta maneira [Aristóteles] compara o intelecto. Quando a alma se liga ao intelecto, quer dizer, às formas | que não possuem matéria nem imagem (fantasya), ${ }^{9}$ [o intelecto] une-se à alma, quer dizer, torna-se existente em ato na alma, e antes disto não era existente nela em ato, mas em potência. Esta forma que não possui matéria nem imagem é o intelecto adquirido pela alma do intelecto primeiro, o qual é a especificidade das coisas, sempre em ato. Enquanto [o intelecto primeiro] é aquele que confere, a alma é o que adquire, pois a alma é inteligente em potência e o intelecto primeiro o é em ato.

[356.5-10] Toda coisa que confere outra coisa por si mesma, aquilo que recebe [algo dela] possui esta coisa em potência, e não em ato. Seja o que for que uma coisa possui em potência, ela não pode passá-la ao ato por si mesma, pois, se [o fizesse] por si mesma, estaria sempre em ato, porque a teria sempre, por si mesma, enquanto fosse existente. Assim, tudo o que está em potência é levado ao ato por outro, este sendo uma coisa em ato. Assim, a alma é inteligente em potência e levada [ao ato] pelo intelecto primeiro quando se liga a ele até se tornar inteligente em ato.

[356.10-13] Quando a forma inteligível se une com [a alma], ela e a forma inteligível não se diferem porque não há divisão que as torne diferentes. Quando [a alma] se une à forma inteligível, ela e o intelecto são uma coisa [só], pois é inteligente e inteligível. Assim, o intelecto e o inteligível são uma coisa [só], relativamente à alma.

8 Isto é, o que sente (faculdade) e o que é sentido (objeto), na alma, são a mesma coisa. Cf. McGinnis; Reismann (2007, p. 17, nota 16).

9 Sigo a sugestão de tradução de Jolivet (1971) e Ramón Guerrero (1986) de que, ainda que o termo designe a faculdade, o sentido é daquilo que dela resulta. 
[356.13-357.3] Quanto ao intelecto que está sempre em ato, que conduz a alma até se tornar em ato inteligente após ter sido inteligente em potência, | ele e o que o intelige ${ }^{10}$ não são uma coisa [só]. Assim, o inteligido na alma e o intelecto primeiro, relativamente ao intelecto primeiro, não são uma coisa [só]; enquanto relativamente à alma, o intelecto e o inteligido são uma coisa [só]. [O inteligido] no intelecto é, relativamente a ser simples, o mais semelhante à alma e muito mais forte do que o [que está no] sensível.

[357.4-358.4] Assim, o intelecto é causa e princípio de todos os inteligíveis e dos intelectos segundos; ou é o segundo [intelecto], que é o que está em potência na alma, enquanto a alma não é inteligente ${ }^{11} \mathrm{em}$ ato; ou é o terceiro [intelecto], que é o que a alma [possui] em ato, | que uma vez que [a alma] o tenha obtido, torna-se para ela existente. Quando [a alma] quer, usa-o, e, a partir dela, torna-o manifesto para existir para outra [coisa] que não [a alma], como o escrever no escritor, pois ela é para ele uma disposição possível que uma vez obtida fica consolidada na alma. Então, [o escritor] exterioriza e usa quando quer. O quarto é o intelecto que se manifesta a partir da alma quando ela o exterioriza, e a partir dela é existente em ato para outra [coisa que não] ela.

[358.5-9] A diferença entre o terceiro e o quarto [intelecto] é que o terceiro é uma aquisição da alma. Uma vez passado o momento de início da aquisição, ela o exterioriza quando quiser. E, [quanto ao] quarto, [ele ocorre] tanto primeiramente, no momento de sua aquisição, quanto posteriormente, no momento de sua manifestação, quando a alma o utiliza. Assim, o terceiro é uma aquisição da alma [feita] previamente, e, quando ela quer, o faz existente nela. $\mathrm{O}$ quarto se manifesta na alma quando se manifesta em ato.

[358.9-15] Louvado seja Deus na medida do que lhe é digno. Estas são as opiniões dos primeiros sábios acerca do... ${ }^{12}$ e acerca do intelecto, e este - seja Deus vosso guia - é o escopo do discurso sobre isto, pois, para o que pedistes, uma exposição simples e instrutiva, basta. Que ela te satisfaça.

Fim da epístola. Louvor a Deus.

\section{Referências}

ABU RIDAH. "Rasa'il al-Kindi al-falsafiyya”. Cairo: Dar al-Fikr al-“Arabi, 1953. ADAMSON. "A Note on Freedom in the Circle of al-Kindi". In: J. E. Montgomery (ed.). 'Abbasid Studies. Leuven: Peeter, 2004. pp. 199-207.

10 Lendo ‘aqil ao invés de ma’qul (inteligido), seguindo Jolivet (1971).

11 Não está inteligindo.

12 Texto faltante. Cf. Jolivet, 1971, p. 157, nota 12. 
ADAMSON. "Al-Kindi and the Reception of Greek Philosophy". In: T. Adamson. Cambridge Companion to Arabic Philosophy, Cambridge, 2010. pp. 32-51.

ADAMSON. "Al-Kindi”. Oxford University Press, 2007 a.

ADAMSON. "The Kindian Tradition: The Structure of Philosophy in Arabic Neoplatonism". In: D'Ancona (ed.). The Libraries of the Neoplatonists: Proceedings of the Meeting of the European Science Foundation Network "Late Antiquity and Arabic Thought. Patterns in the Constitution of European Culture" held in Strasbourg, March 12-14, 2004. Leiden: E. J. Brill, 2007b. pp. 351-70.

ATIYEH. G. N. "Al-Kindi: the Philosopher of the Arabs". Rawalpindi: Islamic Research Institute, 1966.

BADAWI. "Tasdir 'amm”. In: Aristutalis. Fi nafs. Beyruth: Dar al-qalam, 1980.

D'ANCONA. "Aristotelian and Neoplatonic Elements in Kindi's Doctrine of Knowledge". American Catholic Philosophical Quarterly, 73, 1, pp. 9-35, 1999.

ENDRESS. "Building the Library of Arabic Philosophy Platonism and Aristotelianism in the Sources of Al-Kindi". In: D'Ancona (ed.). The Libraries of the Neoplatonists: Proceedings of the Meeting of the European Science Foundation Network "Late Antiquity and Arabic Thought. Patterns in the Constitution of European Culture" held in Strasbourg, March 12-14, 2004. Leiden: E. J. Brill, 2007. pp. 319-350.

ENDRESS. "The Circle of al-Kindi: Early Arabic Translations from Greek and the Rise of Islamic Philosophy". In: Endress; Kruk (eds.). The Ancient Tradition in Christian and Islamic Hellenism. Leiden: Research School CNWS, 1997. pp. 43-76. FAZZO, S.; WIESNER, H. "Alexander of Aphrodisias in the Kindi-Circle and in alKindi's Cosmology". Arabic Sciences and Philosophy, 3, pp. 119-53, 1993.

FITZMAURICE. "Al-Kindi on Psychology". M.A., McGill University (Canada), 1971.

JOLIVET. "L'intellect selon Kindi”. Leiden: E. J. Brill, 1971.

MCcARTHY. "Al-Kindi's Treatise on the Intellect: Text and Tentative Translation". Islamic Studies, 3, 2, pp. 119-149, 1964.

MCGINNIS; REISMANN (eds.). "Classical Arabic Philosophy: An Anthology of Sources". Hackett, 2007.

MOSSA, M. I. "Al-Kindi's Role in the Transmission of Greek Knowledge to the Arabs". Journal of the Pakistan Historical Society, 15, 1967, pp. 1-18.

RAMÓN GUERRERO; TORNERO POVEDA. "Obras filosóficas de al-Kindi". Madrid: Ed. Coloquio, 1986.

RASHED, R.; JOLIVET, J. “Oeuvres Philosophiques et scientifiques d'Al-Kindi”. Métaphisique et cosmologie. Leiden: E. J. Brill, 1998. Vol. 2.

RUFFINENGO. "Al-Kindi. Sull'intelectto, sul sonno e la vision". Medioevo, 23, pp. 347-356, 1997.

TORNERO POVEDA (Ed.). “Al-Kindi: La transformación de un pensamiento religioso en un pensamiento racional". Madrid: CSIC, 1992.

WIESNER. "The Cosmology of al-Kindi”. Ph.D., Harvard University, 1993. 